\title{
Study on Evaluation Method of Aluminum Alloy Pulse MIG Welding Stability Based on Arc Voltage Probability Density
}

\author{
Jing Nie ${ }^{1}$, Xiao-Feng Meng ${ }^{1}$, Yu Shi ${ }^{2}$ \\ ${ }^{1}$ School of Instrumentation Science \& Optoelectronics Engineering, Beihang University, Beijing, China; ${ }^{2}$ Key Laboratory of Non- \\ Ferrous Metal Alloys and Processing of Ministry of Education, Lanzhou University of Technology, Lanzhou, China. \\ Email: niky711@163.com
}

Received February 24 ${ }^{\text {th }}$, 2011; revised April 16 ${ }^{\text {th }}$, 2011; accepted April 25 ${ }^{\text {th }}, 2011$.

\begin{abstract}
Bring forward a new analytical method in order to evaluate the stability of the process of aluminum alloy pulsed MIG welding. The ratio of the first and the second peak in arc voltage signal probability density was selected to evaluate aluminum alloy pulse MIG welding stability. By calculating the arc voltage signal probability density from 80 sets of welding experiments, the ratio of the two peaks in arc voltage probability in every set was captured. And the evaluation system of aluminum alloy pulse MIG welding stability was established. The smaller the ratio of peaks in arc voltage signal probability density is, the better the stability of the welding will be; the bigger the ratio of peaks in arc voltage signal probability density is, the poorer the stability of the welding will be.
\end{abstract}

Keywords: Aluminum Alloy, Pulse MIG, Welding Stability, Probability-Density, Arc Voltage

\section{Introduction}

The process of aluminum alloy pulse MIG welding is characterized by its non-linearity, strong time-varying, strong coupling between the parameters, and so forth [1]. The reason why its process is unstable has not been well explained until now. Because of the lack of the parameter matched stability evaluation indicators, the control of the aluminum alloy pulse MIG welding by changing the welding parameters is very difficult. The fail of matching the parameter will probably lead to the instability in the welding process or even worse. In recent years, many scholars at home and abroad have studied the stability in the welding process: reference [2] put forward an on-line evaluation model of the process stability by use of the statistical analysis and partial least-squares regression. Reference [3] and [4] found that the approximate entropy of the arc signal varied with the change of the parameter. Reference [5] and [6] analyzed the probability density of the corresponding welding current and voltage and finally evaluated the welding stability.

This paper analyzed the probability density distribution of the 80 sets of voltage signal under different welding speed, wire-feeder speed and duty cycle matched parameters.

\section{Experimental System}

The experiment applied DELEX VIRIO MIG-400L welding machine to pure Ar gas shield bead-on-plate welding. The designation of the welding wire was 5356, diameter $1.2 \mathrm{~mm}$. The material of the workpiece was aluminum50581-H321 with the thick of $6 \mathrm{~mm}$. The torch was fixed during welding. And its distance between the workpiece was unchanging. The workpiece moved on the worktable. The initial wire extension was $15 \mathrm{~mm}$. Data acquisition card PCL812PG was applied to the welding and its frequency was $1 \mathrm{kHz}$. The current sensor was CSM400FA/100 mA. The time between the arc igniting and ending was not less than $45 \mathrm{~s}$. Video acquisition captured the condition of the arc and molten pool to judge the stability of the welding. Figure 1 was the experimental system.

Because of the finding that the duty cycle of the pulse current, the wire-feeder speed and welding speed impact the welding stability greatly, the experiment combined the duty cycle, the wire-feeder speed and the welding speed to weld. The base value of the welding current was $25 \mathrm{~A}$, the peak value $180 \mathrm{~A}$, pulse frequency $40 \mathrm{~Hz}$, welding voltage $18 \mathrm{~V}$, and shielding airflow $18 \mathrm{~L} / \mathrm{min}$.

Because the aluminum alloy pulse MIG welding was 


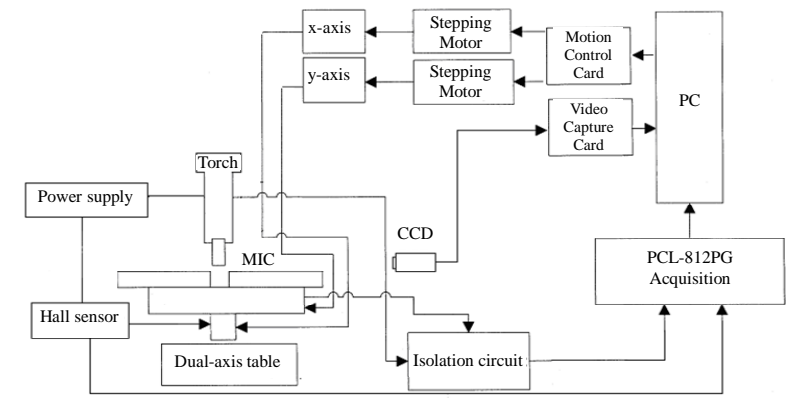

Figure 1. Experimental system.

very strict to its parameter matching, the welding parameters in Table 1 were fixed through the welding experiments. These parameters could be combined randomly. The maximum and minimum of single parameter was the upper and lower limits of the matching. $5 \times 4 \times 4$ sets of welding experiments were conducted and 80 sets of arc voltage signals were acquired.

\section{Voltage Signal Probability Distribution Analysis}

With regard to time array $x(t)$, when amplitude falls on the range $(x, x+\Delta x)$, the total time is $T_{x}=\sum_{i=1}^{k} \Delta t$. When observation time tends to infinity, array $T / T_{X}$ is the probability of case $[x<x(t)<x+\Delta x]$, which can be written as $P[x<x(t)<x+\Delta x]=\lim _{T \rightarrow \infty} T_{x} / T$ the probability density function can be defined as:

$$
\begin{aligned}
P_{x} & =\lim _{\Delta x \rightarrow 0} \frac{\mathrm{P}[\mathrm{x}<\mathrm{x}(\mathrm{t}) \leq \mathrm{x}+\Delta \mathrm{x}]}{\Delta \mathrm{x}} \\
& =\lim _{\Delta x \rightarrow 0} \frac{1}{\Delta x}\left[\lim _{T \rightarrow \infty}\left(\frac{T_{x}}{T}\right)\right]=\lim _{\substack{\Delta x \rightarrow 0 \\
T \rightarrow \infty}}\left(\frac{1}{T_{\Delta x}} \sum_{i=1}^{k} \Delta t_{i}\right)
\end{aligned}
$$

Probability density function $p(x)$ constantly equals to real-value non-negative function. The data must be standardized before analyze its probability density. Every variable minus the mean and then divided by its standard deviation, supposing the collected good-running data matrix is $X \in R^{n \times p}$, each column corresponds to a variable

Table 1 .Welding parameters.

\begin{tabular}{ccc}
\hline $\begin{array}{c}\text { Welding speed } \\
\mathbf{c m} / \mathbf{m i n}\end{array}$ & $\begin{array}{c}\text { Wire feed speed } \\
\mathbf{m} / \mathbf{m i n}\end{array}$ & $\begin{array}{c}\text { Duty cycle } \\
\mathbf{\%}\end{array}$ \\
\hline 11 & 6 & 50 \\
15 & 6.5 & 44 \\
20 & 7 & 40 \\
25 & 7.3 & 37.5 \\
31 & & \\
\hline
\end{tabular}

and each line corresponds to a sample. Standardized the $X$ as follows:

$$
X_{s}=\left[X-(11 \cdots 1)^{T} P\right] \operatorname{diag}\left(\frac{1}{s_{1}}, \frac{1}{s_{2}}, \cdots, \frac{1}{s_{p}}\right)
$$

$P$ - the mean of variable $X$, $P=\left[\frac{1}{S_{1}}, \frac{1}{S_{2}}, \cdots, \frac{1}{S_{p}}\right], S$-the standard deviation of the variable, $S=\left[s_{1}, s_{2}, \cdots, s_{p}\right]$. Then, normalize the standardized data. Finally, calculate and analyze the probability density.

Analyze the probability density of 4 sets of voltage signal selecting from 80 sets of welding experiments arranging from good to bad. Every set of voltage signal cut from the $10^{\text {th }}$ second and 30000 points were captured, namely 30 seconds. The results are shown in Figure 2.

According to Figure 2, two peak values were found in each set of probability density distribution figure and the distance between the two peaks increase. In order to get the accurate variation of the two peaks from 4 sets of experiments, the ratio of the first peak and the second peak was selected to reflect the variation of the distance between the two peaks. The variation of the ratio was shown in Figure 3.

The ratio of the two voltage probability density peaks gradually increase in the four sets of experiments. After comparing the corresponding weld bead, it was found that the ratio of peaks was small when the weld bead shaping was good, and the opposite was big. The second set and the fourth set were shown in Figure 4. Obviously, the weld bead of the second set was better than that of the fourth. And the ratio of peaks of the second set was smaller than that of the fourth. Therefore, the ratio of the two peaks in voltage probability can be applied to evaluate the stability of aluminum allay MIG welding.

\section{Evaluation System of Welding Stability}

According to the result above, 80 sets of welding voltage signal was calculated for probability density. By making use of the ratio of the two peaks in each set of voltage signal probability density, the evaluation system of aluminum alloy pulse MIG welding stability was established. The result is shown in Figures 5-7. What is shown in Figures 5-7 is the fluctuation of the ratio of peaks in arc voltage signal probability density under different parameter. The figure well reflects the aluminum alloy pulse MIG welding stability under different welding speed, wire feed speed and duty cycle. In aluminum alloy pulse MIG welding, the smaller the ratio of peaks in arc voltage signal probability density is, the better the stability 


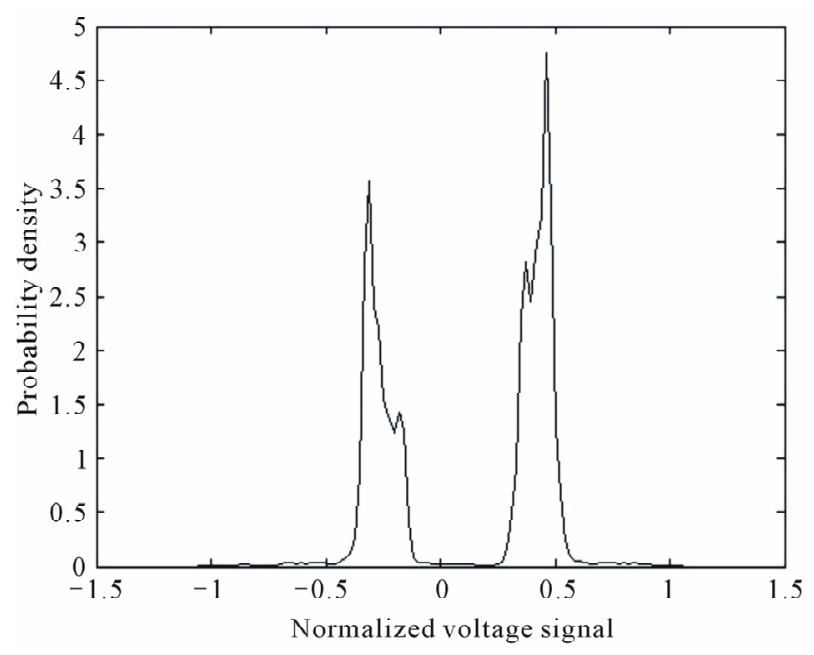

(a)

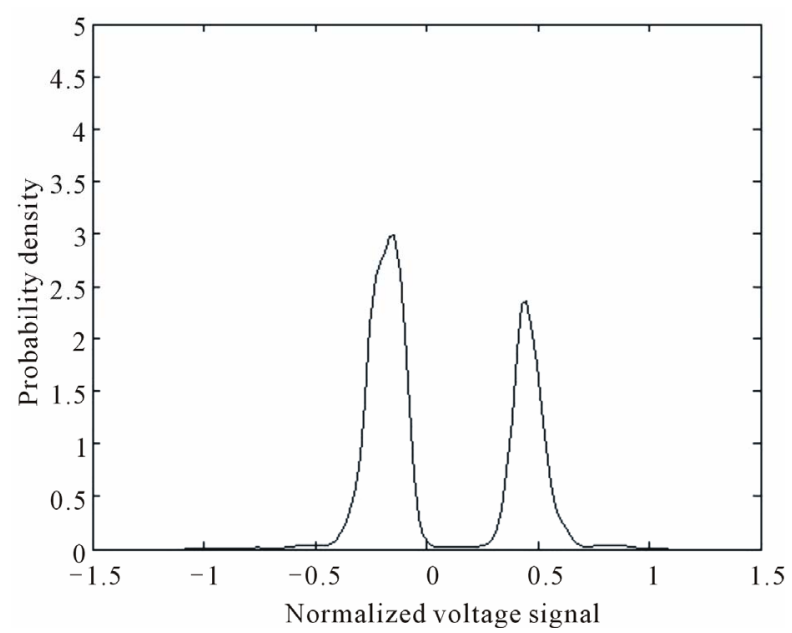

(c)

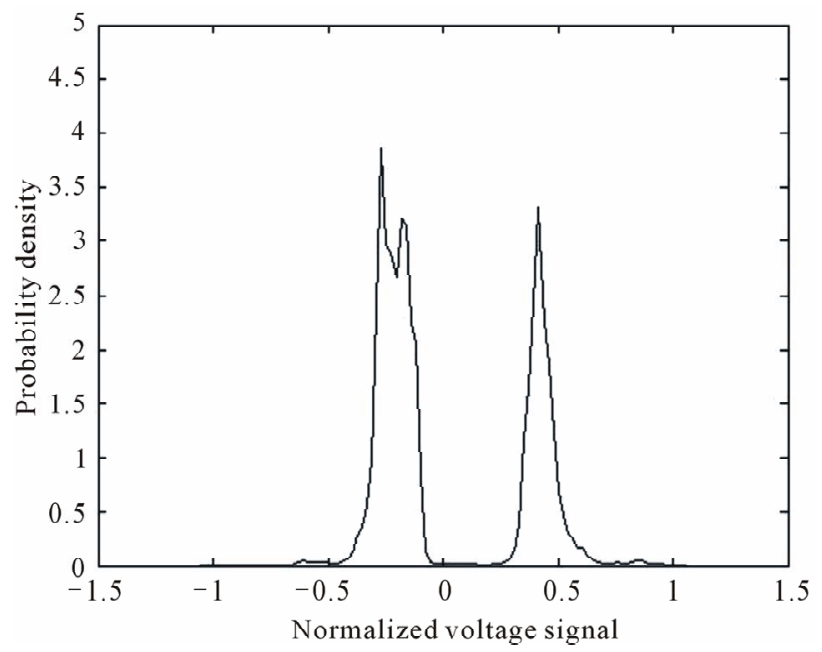

(b)

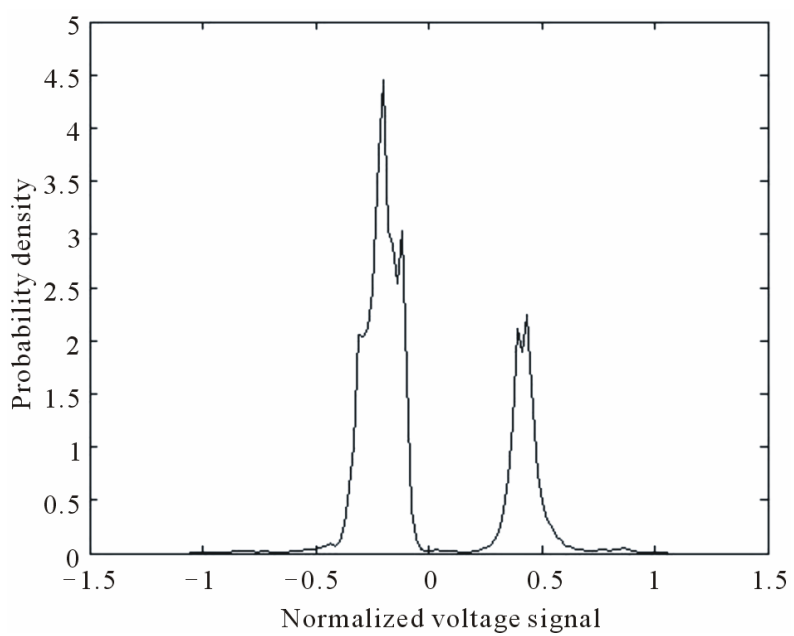

(d)

Figure 2. Probability density of voltage. (a) NO.1; (b) NO.2; (c) NO.3; (d) NO.4.

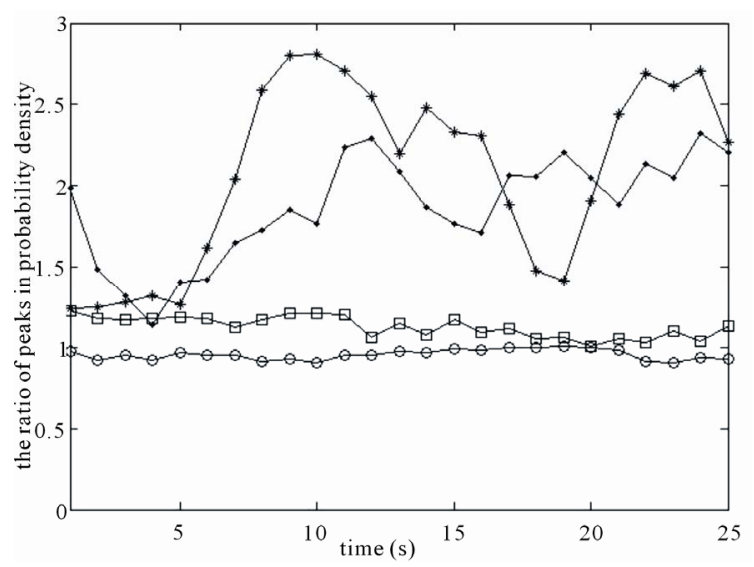

Figure 3. Changes in the ratio of peaks in probability density.

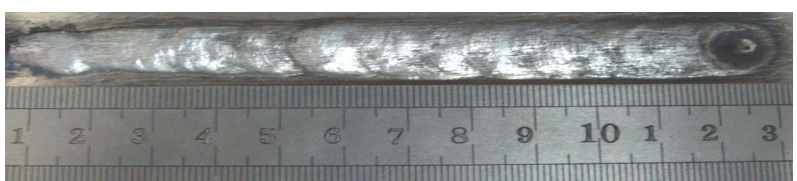

(a)

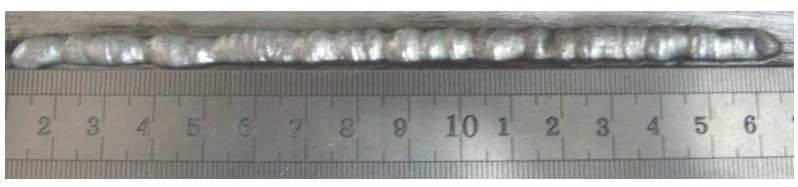

(b)

Figure 4. The weld of different parameters. (a) NO.1; (b) NO.4. 


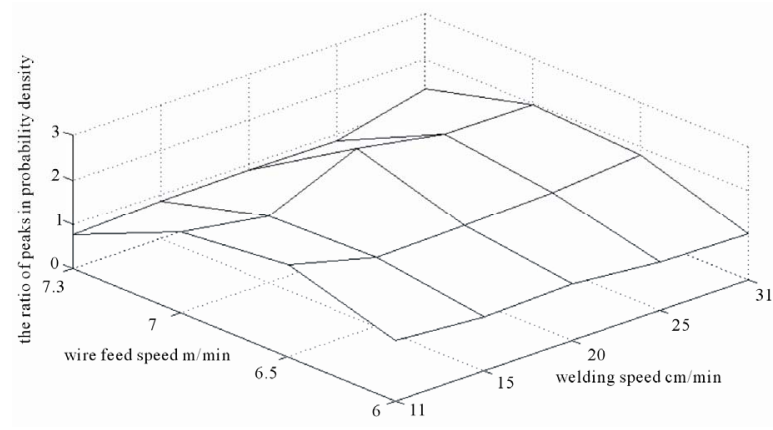

(a)

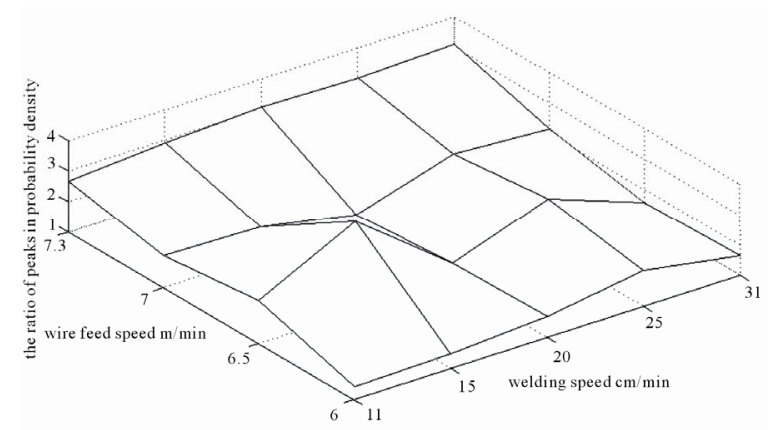

(c)

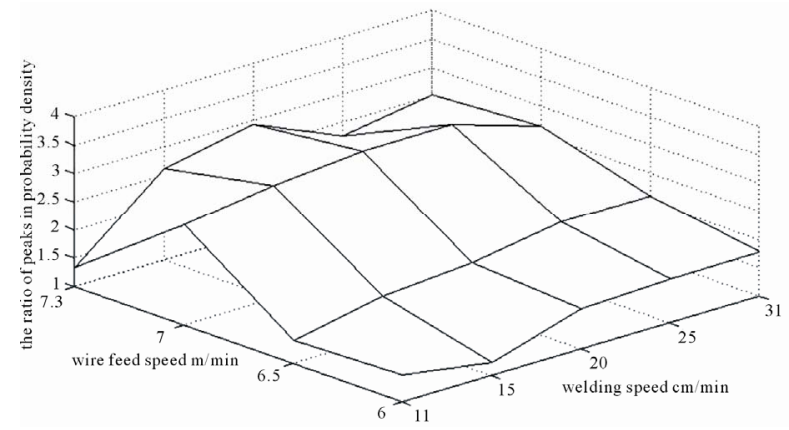

(b)

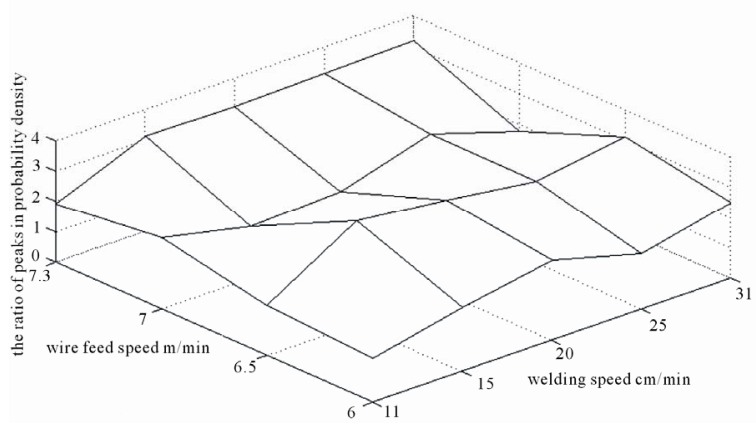

(d)

Figure 5. The match of welding and wire feed speeds on different duty cycle. (a) duty cycle 50\%, (b) duty cycle $44 \%$, (c) duty cycle $40 \%$, (d) duty cycle $37.5 \%$.

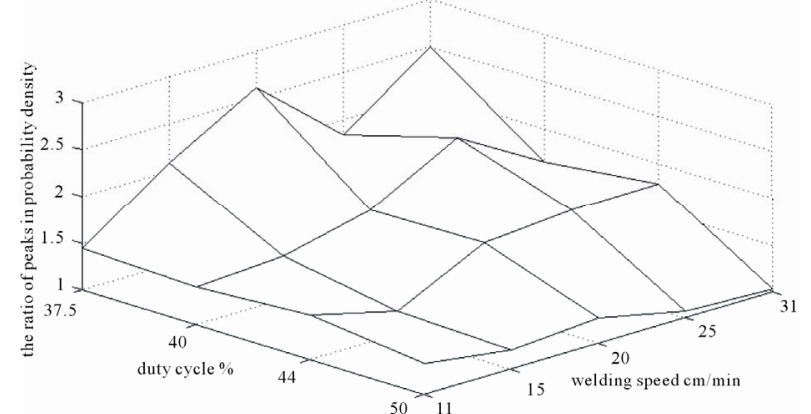

(a)

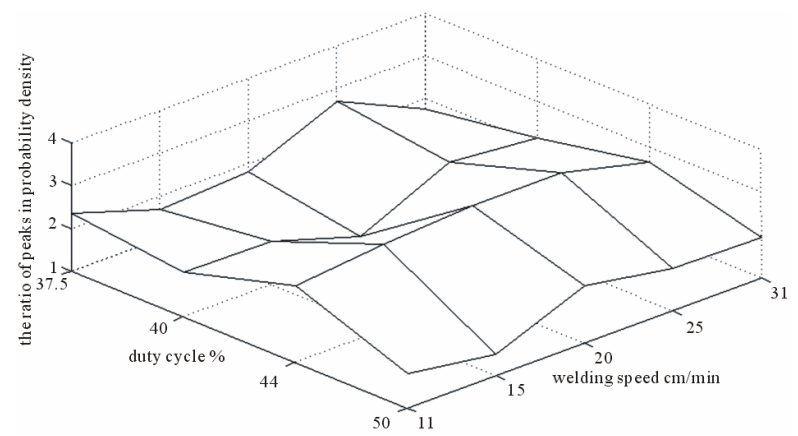

(c)

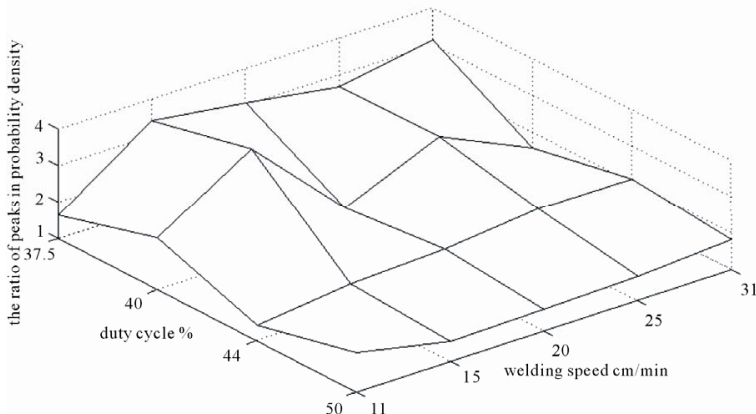

(b)

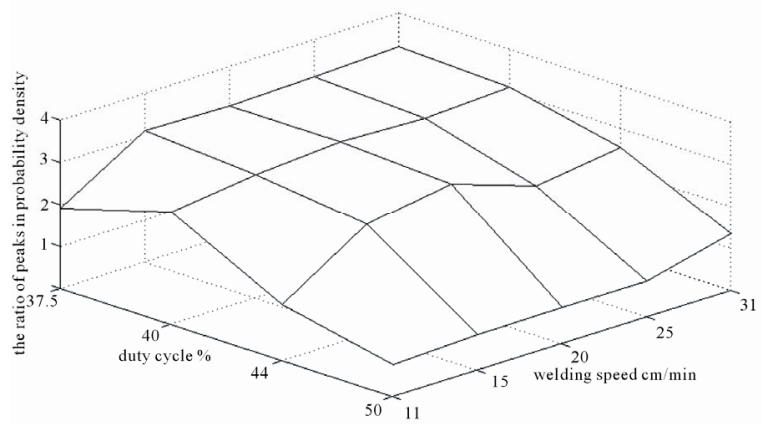

(d)

Figure 6. The match of welding speeds and duty cycle on different wire feed speeds. (a) wire feed speed $6 \mathrm{~m} / \mathrm{min}$; (b) wire feed speed $6.5 \mathrm{~m} / \mathrm{min}$; (c) wire feed speed $7 \mathrm{~m} / \mathrm{min}$; (d) wire feed speed $7.3 \mathrm{~m} / \mathrm{min}$. 


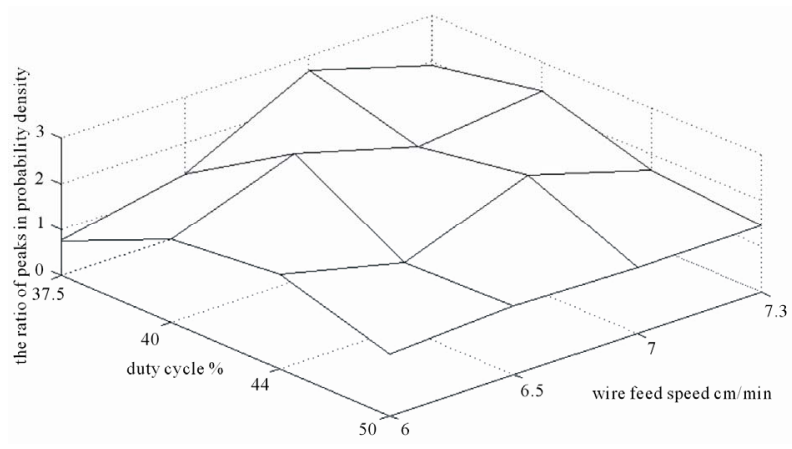

(a)

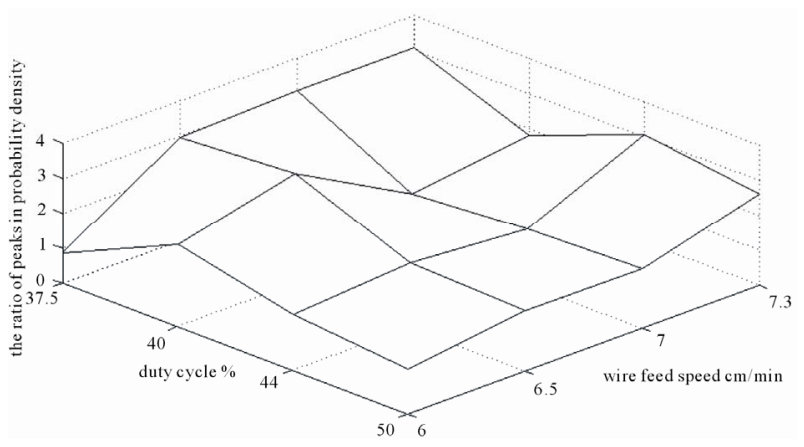

(c)

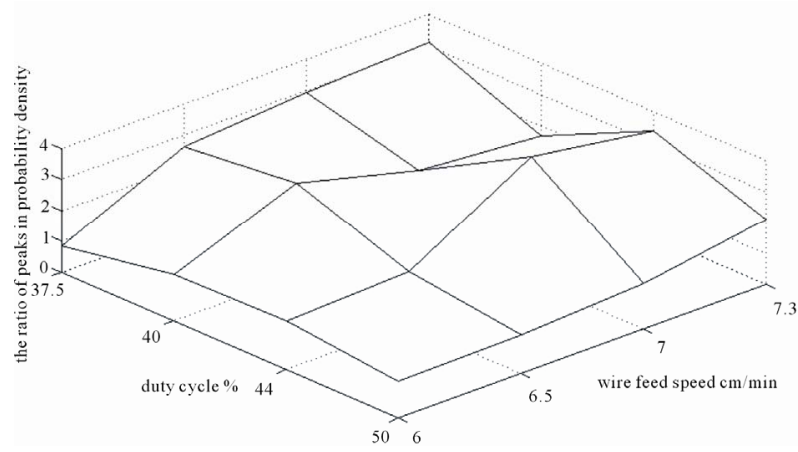

(b)

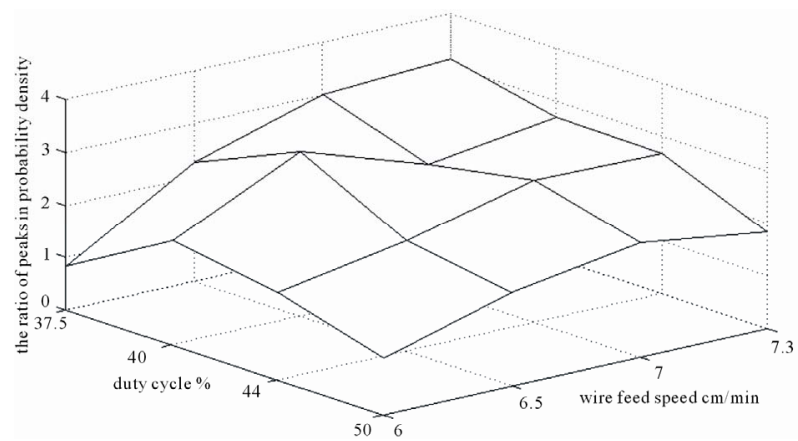

(d)

Figure 7. The match of wire feed speeds and duty cycle on different welding speeds. (a) welding speed $11 \mathrm{~cm} / \mathrm{min}$; (b) welding speed $15 \mathrm{~cm} / \mathrm{min}$; (c) welding speed $20 \mathrm{~cm} / \mathrm{min}$; (d) welding speed $25 \mathrm{~cm} / \mathrm{min}$.

Table 2. The ratio of peaks in voltage probability density and weld forming under different welding parameters.

\begin{tabular}{|c|c|c|c|c|c|c|}
\hline Number & Wire feed speed m/min & Duty cycle \% & $\begin{array}{l}\text { Welding speed } \\
\mathrm{cm} / \mathrm{min}\end{array}$ & $\begin{array}{l}\text { Ratio of peaks in } \\
\text { probability density }\end{array}$ & Stability & Welding forming \\
\hline 1 & 6 & 50 & 11 & 1.3333 & Stable & Good \\
\hline 2 & 6 & 44 & 15 & 1.24 & Stable & Good \\
\hline 3 & 6 & 37.5 & 20 & 2.6111 & Unstable & Bad \\
\hline 4 & 6.5 & 44 & 25 & 2.1 & Unstable & Bad \\
\hline 5 & 6.5 & 40 & 15 & 4 & Unstable & Bad \\
\hline 6 & 6.5 & 37.5 & 20 & 3.0625 & Unstable & Bad \\
\hline 7 & 7 & 44 & 11 & 2.7778 & Unstable & Bad \\
\hline 8 & 7 & 40 & 25 & 2.35 & Unstable & Bad \\
\hline 9 & 7.3 & 50 & 20 & 0.8649 & Stable & Good \\
\hline
\end{tabular}

of the welding will be. The opposite is the instability of the welding.

Table 2 shows the ratio of peaks in voltage probability density and weld forming under different welding parameters, through which the ratio of peaks in arc voltage signal probability density and the welding stability can be compared more objectively.

\section{Conclusions}

1) By analyzing the ratio of peaks in arc voltage signal probability density and comparing the welding bead, the ratio of peaks in aluminum alloy pulse MIG welding arc voltage signal probability density is suitable to be applied to evaluate the welding stability. 
2) According to the fluctuation condition of the ratio of peaks in arc voltage signal probability density, the evaluation system of aluminum alloy pulse MIG welding stability is established. The smaller the ratio of peaks in arc voltage signal probability density is, the better the stability of the welding will be; the bigger the ratio of peaks in arc voltage signal probability density is, the poorer the stability of the welding will be.

\section{Acknowledgements}

This paper is supported by the National Natural Science Foundation of China under Grant No.50675093 and National Natural Science Foundation of International Cooperation under Grant No.50710105060. Thanks for help from Key Laboratory of Non-ferrous Metal Alloys and Processing of Ministry of Education, Lanzhou University of Technology.

\section{REFERENCES}

[1] S. Yamada and K. Masubuchi, “Advanced Welding Technology Keeps Japan’s High-Speed Trains on Trac,”
Welding Journal, Vol. 79, No. 11, November 2000, pp. 48-53.

[2] Y. Cai, H. L. Yang, K. Xu and Y. X. Wu, “An On-line Evaluation Model for Process Stability of Short-Circuit Arc Welding," Journal of Shanghai Jiaotong University, Vol. 39, No. 7, July 2005, pp. 1038-1041.

[3] R. T. Charles, A. L. Randall and B. S. Herschel, "Is There Evidence of Determinism in Droplet Detachment within the Gas Metal Arc Welding Process,” 6th International Conference on Trends in Welding Research, April 2002.

[4] B. Cao, X. Q. Lv, M. Zeng and S. S. Huang, “Analysis of Welding Conditions in Short-Circuiting Transition Base on Approximate Entropy," Chinese Journal of Mechanical Engineering, Vol. 43, No. 10, October 2007, pp. 50-54. doi:10.3901/JME.2007.10.050

[5] Y. Zhang, X. Xu and Y. Cai, "Collection and Analysis System of Welding Parameters Based on LabView," Transactions of the China Welding Institution, Vol. 24, No. 4, August 2003, pp. 43-46.

[6] F. S. Wu, Z. L. Lu and Z. F. Liu, "Study on the Process Parameter Monitoring and Analysis System of SAW Submarine Shell," China Mechanical Engineering, Vol. 15, No. 7, April 2004, pp. 621-624. 